\title{
Clinical and biochemical predictors of late-outcome in patients after ischemic stroke
}

\author{
Joanna Ewa Bielewicz ${ }^{1, A \oplus}$, Jacek Kurzepa ${ }^{2, C \oplus}$, Piotr Kamieniak ${ }^{3, B}{ }^{\circ}$, Beata Daniluk ${ }^{4, C} \oplus$, \\ Anna Szczepańska-Szerej ${ }^{1, E \oplus}$, Konrad Rejdak ${ }^{1, F} \odot$ \\ ${ }^{1}$ Department of Neurology, Medical University, Lublin, Poland \\ ${ }^{2}$ Department of Medical Chemistry, Medical University, Lublin, Poland. \\ ${ }^{3}$ Department of Neurosurgery, Medical University, Lublin, Poland \\ ${ }^{4}$ Institute of Psychology, Marie Curie-Skłodowska University, Lublin, Poland \\ A - Research concept and design, B - Collection and/or assembly of data, C - Data analysis and interpretation, \\ $D$ - Writing the article, E-Critical revision of the article, F - Final approval of article
}

Bielewicz JE, Kurzepa J, Kamieniak P, Daniluk B, Szczepańska-Szerej A, Rejdak K. Clinical and biochemical predictors of late-outcome in patients after ischemic stroke. Ann Agric Environ Med. 2020; 27(2): 290-294. doi: 10.26444/aaem/105927

\section{Abstract}

Objective. The aim of this study is to evaluate neurological scales, as well as biochemical and radiological parameters measured on day 10 after ischemic stroke (IS), according to their value as predictors of the long-term outcome.

Materials and method. 45 patients were assessed according to the Barthel Index (BI) and National Institute of Health Stroke Scale (NIHSS) on day 10, and according to Modified Rankin Scale (mRS) 3 months after the onset of IS. On day 10 of IS, the serum level of C-reactive protein (CRP), albumin, D-dimers (DD), S100BB and Tau proteins was measured and the volume of ischemic focus assessed with the use of Computed Tomography (CT). The patients were divided into groups with good outcome (GO) and $\mathrm{mRS} 0-2$, and with bad outcome (BO) and mRS 3-6.

Results. NIHSS and BI scores $(p<0.001)$, the volume of ischemic focus $(p<0.01), C R P(p<0.01)$ and albumin level $(p<0.05)$, but not DD, S100BB and Tau protein levels evaluated on day 10, correlated with mRS after 3 months since IS onset. Patients from the BO group were observed to have lower $\mathrm{BI}(p=0.001)$, higher NIHSS $(p<0.01)$ and CRP levels $(p<0.05)$, and bigger volume of ischemic focus $(p<0.05)$ measured on day 10 of IS. In the GO group, there were more patients with atherosclerotic etiology $(p=0.02 \times 2=7.856)$. Regression analysis showed that only the BI score assessed on day 10 of IS can predict the outcome after 3 months assessed by mRS (OR=1.102, 95\%, Cl:1.01-1.203; $\mathrm{p}=0.001)$.

Conclusions. Bl assessed on day 10 has a predictive value for the outcome evaluated by mRS 3 months after the onset of IS.

\section{Key words}

CRP, outcome, Ischemic stroke, MRS, Barthel index, NIHSS.

\section{INTRODUCTION}

The possibility of prognosis of long-term outcome in people affected by ischemic stroke (IS) is a matter of great importance for patients, their caregivers and doctors working in stroke units (SU). SU patients are hospitalized for a defined, rather short period of time. Accurate prognosis concerning the outcome can help to plan the rehabilitation process and determine the need for care of caregivers. Many factors including demographic features, clinical scales and biochemical parameters have been assessed until the present according to their usefulness as predictors $[1,2,3]$.

The National Institute of Health Stroke Scale (NIHSS) is a very popular scale for scoring neurological deficits by assessing 11 neurological deficits and their degree of intensity. The final score can vary from $0-42$ points. It is also considered a valuable tool for measuring long-term outcome after stroke IS $[4,5,6]$. Additionally, analysis of the NIHSS score is used as a method for assessing the efficacy of the services for IS patients [7] and has been widely used in clinical trials [8].

There are also other widely used scales for functional assessment, such as the Barthel Index (BI) and the modified

Address for correspondence: Joanna Ewa Bielewicz, Department of Neurology, Medical University of Lublin, Poland

E-mail: j.bielewicz@op.pl

Received: 15.09.2019; accepted: 25.03.2019; first published: 08.04.2019
Rankin Scale (mRS). In 1965, BI was offered as modification of the 'Maryland disability index' and began to be used as a valuable tool for assessing improvement in rehabilitation [9]. The scale describes 10 tasks. Each task is scored according to the possibility of its independent performance by patients, with a total score from 0-100 [9]. Some suggested key cut-off points with less than 40 points indicate complete dependence on others [10]. However, BI was not designed for stroke patients. It has many limitations which can over- or underestimate the possibility of independent functioning by stroke patients. Despite that, BI can be useful as a measure which can predict the long-term outcome after ischemic, hemispheric stroke [2,11,12].

The mRS is the globally used scale dedicated to patients who suffered a stroke. The scale measures the degree of dependence in the activities of daily living, according to categorized subjects in 7 groups, from $0-6$. In spite of its limitations concerning reliability, mRS remains the most prevalent functional outcome measure with no restriction on the age of patients $[13,2]$.

The measure of initial infarct size is a strong and independent predictor of IS outcome in long-term observations [14, 15].

In many studies, predictive values of routinely assessed biochemical substances have been validated [16]. Among them, C-reactive protein (CRP) [17, 18, 19], albumin [20, 21] and D-dimers (DD) $[22,23]$ can be considered as determinants of long-term outcome. 
Numerous studies have been devoted to discover biochemical markers of the neurological diseases that could be useful as diagnostic or prognostic indicators. These substances are released into the cerebrospinal fluid (CSF) [24] and later into the bloodstream during different processes of ischemia [24, 25]. S100BB protein is a well-known glial cell marker and its increased level can predict unfavourable outcome after IS $[1,26,27]$. Tau protein, released from axons during ischemia, has also become an object of interest as a predictive factor $[28,29]$ and therapeutic target for IS [30].

\section{OBJECTIVE}

The aim of the prospective study is to evaluate different clinical scales, biochemical and radiological parameters measured on day 10 after the stroke onset, according to their value as predictors of long-term outcomes. The day of measurement was chosen as a mean stay at SU in 10 days. As the endpoint, the mRS score after 90 days since the onset of IS was chose. The mRS has some limitations but it is a globally used scale, clearly and directly indicating the possibility of independent functioning of patients after IS in their daily environment. Global disability on days 7-10 after suffering IS strongly predicts the final 3-month disability outcome [31]. Additionally, previous studies have proved its high sensitivity as the end point for detecting treatment effect [32].

\section{MATERIALS AND METHOD}

Sixty patients admitted to the Stroke Unit in the Department of Neurology of the Medical University in Lublin, Eastern Poland, were prospectively enrolled into the study. All patients (or their family members) received full written and oral information regarding all study procedures, and signed an informed consent. The Ethics Committee of the Medical University in Lublin approved the protocol and the informed consent. Inclusion criteria were: (a) diagnosis of IS based on history, physical examination and computed tomography (CT) performed upon admission to the hospital, (b) admission to the hospital within the first 24 hours of the onset of neurological focal symptoms. Exclusion criteria were: (a) regression of neurological symptoms within 24 hours of the onset (Transient Ischemic Attack, TIA), (b) previous history of central nervous system diseases, (c) time of hospitalization shorter than 10 days, (d) haemorrhagic transformation of ischemic focus, (e) recurrent stroke. All patients did not fulfill the criteria for r-tPA treatment. The final study group consisted of 45 patients. Rehabilitation was applied to all patients which consisted of passive or active exercises, according the patient's status, 30-40 minutes once a day.

Neurological Assessment. Neurological examination was performed on day 1 and day 10 after admission to hospital, based on the scales: NIHSS, BI and mRS. After 3 months, 38 patients were examined according to BI and mRS by phone. 7 patients died within 3 months of their discharge from hospital.

Imaging studies. A CT-scan was performed on day 10 day (additionally to that performed on admission) of hospitalization, without contrast, using a 64-row multidetector CT (LightSpeed VCT with workstation Advantage Window 4.3). The volume and mean density of ischemic foci were measured by means of the planimetric method, with the use of an additional workstation for measuring infarct volume in $3 \mathrm{D}$.

Biochemical procedures. Venous blood samples were obtained during the first 24 hours after stroke and on day 10 day onset of symptoms (fasting specimens at the same time in the morning). After centrifugation, sera was stored at $-60^{\circ} \mathrm{C}$ for a maximum period of 8 months. Commercially available enzyme-linked immunosorbent assay (ELISA) kits were used to evaluate serum S100BB (CanAg Diagnostics AB, Gothenburg, Sweden), Tau protein (Innotest, Innogenetics NV, Gent, Belgium), CRP (R\&D Systems Inc.Minneapolis, USA) and DD levels (Innovance, Siemens Health Diagnostics Products GmbH, Marburg, Germany), according to the manufacturer's instructions. Detection limit of S100BB and Tau protein was $10 \mathrm{pg} / \mathrm{mL}$ and $60 \mathrm{pg} / \mathrm{mL}$, respectively. All values below detection limit were rendered zero and not used in calculations. Optical density was determined by use of a microplate reader set at $450 \mathrm{~nm}$. The cut-off value for DD was $500 \mu \mathrm{g} / \mathrm{L}$. Measurement of albumin serum level was based on electrophoretic methods.

Statistical analysis. Statistical analysis was performed with the use of the SPSS (Statistical Package for Social Sciences) software for Windows (Version 20.0). The average standard deviation and percentiles were provided for descriptive analysis. Statistical differences between non-dependent groups were calculated using the Mann-Whitney U test and the $\chi^{2}$ test. Wilcoxon signed ranks test was used to compare the two dependent groups. The Spearman rank correlation test (R) was employed to search for correlation between the functional status and levels of CRP, albumin, DD, S100BB and Tau proteins, and volume of ischemic focus. Logistic regression modeling was was used to identify predictors of good and bad outcomes 3 months after stroke. $p<0.05$ was accepted as statistically significant. Multiple logistic regression using the backward stepwise method was applied, and for the criterion of removal variables, the test of likelihood ratio was used. The probability of removing variables was 0.06 . All explanatory variables introduced into the model were quantitative.

\section{RESULTS}

Ultimately, 45 patients with IS were evaluated: 23 women and 22 men, of whom 27 (60\%) were atherosclerotic, 10 (23\%) cardioembolic and 7 (16\%) were of undefined etiology. Patients were between 50-93-years-old. The average age was $72.42(\mathrm{SD}=11.18)$.

Significant correlations were observed between NIHSS and BI evaluated on day 10 of IS, and mRS 3 months after IS onset $(\mathrm{R}=0.533 ; \mathrm{p}<0.001, \mathrm{R}=-0.525 ; \mathrm{p}<0.001$, respectively). Positive correlation between volume of ischemic focus measured on day 10 of IS and the late outcome was also noted ( $\mathrm{R}=0.45$; $\mathrm{p}<0.01)$. Among the biochemical factors which can influence IS outcome and were evaluated on day 10 of IS, CRP and albumin levels, but not DD level, correlated with results of $\mathrm{mRS}$ after 3 months $(\mathrm{R}=0.42 ; \mathrm{p}<0.01$ and $\mathrm{R}=0.41 ; \mathrm{p}<0.05$ for 
Table 1. Clinical and biochemical characteristics in ischemic stroke patients on day 10 after stroke

\begin{tabular}{lc}
\hline Variable & $\begin{array}{c}\text { Group }(\mathrm{N}=45) \\
\text { Mean }(\mathrm{SD})\end{array}$ \\
\hline NIHSS & $8.13(6.04)$ \\
\hline Barthel Index (BI) & $43.33(39.91)$ \\
\hline Modified Rankin Scale $(\mathrm{mRS})$ & $3.62(1.76)$ \\
After 10 days & $3.42(1.86)$ \\
After 3 months & $40.06(70.65)$ \\
\hline Volume of ischemic focus $(\mathrm{mL})$ & $44.67(27.17)$ \\
\hline S100BB $(\mathrm{pg} / \mathrm{mL})$ & $46.97(88.52)$ \\
\hline Tau $(\mathrm{pg} / \mathrm{mL})$ & $25.95(26.96)$ \\
\hline $\mathrm{CRP}(\mu \mathrm{g} / \mathrm{mL})$ & $1393.32(1450.53)$ \\
\hline D-dimer $(\mu \mathrm{g} / \mathrm{L})$ & $3.72(0.64)$ \\
\hline Albumin $(\mathrm{g} / \mathrm{dL})$ &
\end{tabular}

CRP and albumin, respectively). There were no significant correlations between S100BB and levels of Tau proteins on day 10 and mRS 3 months after onset of IS.

Patients were divided into two groups in terms of results of their late outcome (90 days after stroke onset). The first group was with good outcome (GO) and consisted of patients without neurological deficits or with disability that did not affect their independence (mRS 0-2). The second group was with bad outcome (BO), and consisted of patients dependent on others or of those who died (mRS 3-6).

13 people $(28.88 \%)$ were in the GO and $32(71.22 \%)$ in the $\mathrm{BO}$ group (including 7 who died).

There were no statistical differences between the two groups in terms of age and gender. There were more patients with atherosclerotic etiology in GO than in $\mathrm{BO}(\mathrm{p}=0.02$

Table 2. Comparison of demographic, clinical and biochemical characteristics in patients with good (mRS 0-2) and bad (mRS 3-6) outcome 3 months after ischemic stroke (Mann-Whitney $U$ test or $\mathrm{c}^{2}$ test).

\begin{tabular}{|c|c|c|c|c|}
\hline Variable & $\begin{array}{c}\mathrm{GO}(\mathrm{mRS} 0-2) \\
\text { mean }(\mathrm{SD}) \\
\mathrm{n}=13\end{array}$ & $\begin{array}{c}\mathrm{BO}(\mathrm{mRS} 3-6) \\
\text { mean }(\mathrm{SD}) \\
\mathrm{n}=32\end{array}$ & $\mathrm{U} / \mathrm{c}^{2}$ test & $\begin{array}{c}\mathrm{p}- \\
\text { value }\end{array}$ \\
\hline Age & 68.69 (9.19) & $73.94(11.7)$ & 1.443 & 0.156 \\
\hline Male/female & $9 / 4$ & $13 / 19$ & 3.027 & 0.082 \\
\hline $\begin{aligned} & \text { Etiology of IS } \\
&- \text { atherosclerosis } \\
&- \text { cardioembolism } \\
& \text { - undefined }\end{aligned}$ & $\begin{array}{c}0 \\
12 \\
1\end{array}$ & $\begin{array}{c}10 \\
15 \\
7\end{array}$ & $7.856^{*}$ & 0.02 \\
\hline $\begin{array}{l}\text { Volume of ischemic } \\
\text { focus (mL) }\end{array}$ & $6.23(8.11)$ & $54.38(80,28)$ & $-2.542^{*}$ & 0.011 \\
\hline $\begin{array}{l}\text { NIHSS } \\
\text { on day } 10\end{array}$ & $4.54(6.06)$ & $9.59(5,47)$ & $-2.875 * *$ & 0.004 \\
\hline $\begin{array}{l}\text { Barthel Index } \\
\text { on day } 10\end{array}$ & $76.54(32.81)$ & $29.84(34,56)$ & $-3.316^{* * *}$ & 0.001 \\
\hline $\begin{array}{l}\mathrm{S} 100 \mathrm{~B}(\mathrm{pg} / \mathrm{mL}) \\
\text { on day } 10\end{array}$ & $43.40(20.73)$ & $45.16(29,58)$ & -0.068 & 0.946 \\
\hline $\begin{array}{c}\text { Tau }(\mathrm{pg} / \mathrm{mL}) \\
\text { on day } 10\end{array}$ & $20.62(40.48)$ & $57.67(100,39)$ & -1.075 & 0.283 \\
\hline $\begin{array}{c}\mathrm{CRP}(\mu \mathrm{g} / \mathrm{mL}) \\
\text { on day } 10\end{array}$ & $12.80(14.21)$ & $31.39(29,23)$ & $-2.378^{*}$ & 0.017 \\
\hline $\begin{array}{l}\text { D-dimer }(\mu \mathrm{g} / \mathrm{L}) \\
\text { on day } 10\end{array}$ & 1550.54 (1902.97) & $1328.27(1252.26)$ & -0.244 & 0.808 \\
\hline $\begin{array}{c}\text { Albumin }(\mathrm{g} / \mathrm{dL}) \\
\text { on day } 10\end{array}$ & $3.80(0.97)$ & $3.69(0.43)$ & -1.640 & 0.101 \\
\hline
\end{tabular}

$\mathrm{x} 2=7.856)$. Patients from the $\mathrm{BO}$ group had significantly lower $\mathrm{BI}(\mathrm{p}=0.001)$, higher NIHSS $(\mathrm{p}<0.01)$ and CRP level $(\mathrm{p}<0.05)$, and bigger volume of ischemic focus $(\mathrm{p}<0.05)$ measured on day 10 of IS. Other parameters were not statistically significant.

Logistic regression was used to investigate the predictive value of clinical and biochemical parameters measured on 10 day for the functional outcome after IS. Only BI score assessed on 10 day of IS and no other parameters, can predict the outcome after 3 months assessed by mRS (OR=1.102, 95\%, CI:1.01-1.203; $\mathrm{p}=0.001$ ).

Predicting late recovery 3 months after the onset of IS remains difficult because of factors such as co-morbidities, social environment and personality traits, which additionally co-influence patients with a neurological state. Functional recovery rates varied considerably among hospitals [3].

The results of the current study show that the most valuable among analyzed parameters is BI assessment. BI score assessed on day 10 not only negatively correlated with mRS 3 months after the onset of IS, but also indicated that patients would be in the group with poorer outcome, and more dependent on others considering the daily activities or dead. This was the only parameter which was a predictor of a late outcome in the model of regression analysis.

According to some studies [33], BI and mRS overlap on day 10 after stroke onset. NIHSS appears to have a lower value as a predictor of late outcome, compared to BI. NIHSS assessed on day 10 of IS, correlated with the outcome 3 months after the onset of IS. The higher the NIHSS score, the higher the probability that a patient will be found in the $\mathrm{BO}$ group. That scale, however, did not reach a statistical significance to be a predictor of clinical outcome in the model of regression analysis. BI more accurately describes a patient's ability to live an independent life, because it assesses the performance of individual daily activities, not neurological deficits that may be compensated.

A CT performed on day 10 day after stroke more precisely showed the volume of ischemic focus, compared with an early CT performed on admission, due to the gradual forming on injury within the first hours and days after suffering an IS. A bigger volume of ischemic focus measured on day 10 of IS, correlated with poorer late outcome and showed that patients may be found in the BO group after 3 months. That observation was also found in some previous studies $[14,15]$.

An interesting finding is that the majority of patients with $\mathrm{GO}$ were of atherosclerotic etiology of IS. Atherosclerosis is a process evolving over time as opposed to embolic stroke. This may allow for the development of collateral circulation and the limitation of injury during IS.

Among biochemical biomarkers, only the CRP level assessed on day 10 suggested a later, adverse outcome. There is data which indicates a relationship between increased CRP and poorer outcome $[17,18,34]$ and long-term mortality after IS [19]. It is a matter of debate whether CRP remains a non-specific marker only or plays an active role during inflammatory processes. Some studies on animal models suggest that CRP is not only a causal factor for stroke, but it also influences blood-brain stability [35] and exacerbates the tissue injury of ischemic necrosis in stroke [36]. CRP is considered to be a possible target for IS treatment [36, 37].

The results obtained in the current study do not confirm an earlier observation that albumin highlighted a favourable influence of serum albumin level on the outcome of patients 
with ischemic stroke (IS) [21, 22]. However, earlier studies took into account the albumin level measured on the first day, and not on day 10 of IS [21].

The value of the DD level as a prognostic factor for longterm outcome after IS is controversial $[23,38]$. The results of the current study support the opinion of those authors who failed to consider DD level as an indicator of late outcome after IS [38].

Specific substances of the nervous tissue which are released into the blood during IS are of great interest as potential predictors. The authors of this study found no correlations between S100BB and Tau proteins, and late outcome. S100BB protein reached a peak level on day 3 of IS; therefore, its evaluation on day 10 showed the limitation of its usefulness as a predictor for late outcome of IS. Tau protein was found in only $43.9 \%$ of patients in the current study, which makes that protein less valuable as a predictor. These results confirm those of a previous study [29] which indicated that detection of Tau protein in the serum of patients with IS, but not its concentration, can be considered as a bad prognostic factor for the clinical outcome in the early and late phases of IS.

The functional status of a patient after stroke is also influenced by factors such as mental status and comorbidities or nutritional status. The neurological deficit caused by IS overlaps the pre-morbid functional status. For this reason, functional (BI), but not biochemical assessment measured on the day of discharge from hospital, is a better predictor of the long-term outcome.

The limitation of this study was the small sample of enrolled patients. This can account for the fact that the results obtained did not consider demographic factors, such as age and gender as important for post-IS prognosis, which is contrary to the results of other authors $[39,40]$. Evaluation of clinical scales was performed at a hospital, which may influence the results due to the possible limitation of a patient's activity by members of staff. However, the presented results are statistically significant which is an important and valuable observation which could direct and inspire further clinical researches.

\section{CONCLUSION}

Among different clinical scales, biochemical parameters and radiological findings, the most useful in long-term prognosis is clinical assessment by BI. BI assessed on day 10 has a predictive value for the outcome evaluated by means of $\mathrm{mRS}$ 3 months after the onset of IS.

\section{REFERENCES}

1. Iemolo F, Sanzaro E, Duro G, Giordano A, Paciaroni M. The prognostic value of biomarkers in stroke. Immun Ageing. 2016; 31(13): 19.

2. Memis D, Kozanoglu E, Kelle B, Goncu MK. Assessment of demographic and clinical characteristics on functional status and disability of patients with stroke. Neurosciences (Riyadh). 2016; 21(4): 352-357.

3. Bettger JP, Thomas L, Liang L, Xian Y, Bushnell CD, Saver JL, et al. Hospital variation in functional recovery after stroke. Circ cardiovasc Qual Outcomes. 2017; 10(1)

4. Muir KW, Weir CJ, Murray GD, Povey C, Lees KR. Comparison of neurological scales and scoring systems for acute stroke prognosis. Stroke. 1996; 27(10): 1817-20.

5. Rost NS, Bottle A, Lee JM, Middleton S, Shaw L, Thijs V, et al. Global Comparators Stroke GOAL collaborators. Stroke severity is a crucial predictor of outcome: an international prospective validation study. J Am Heart Assoc. 2016; 21; 5(1).

6. Bhaskar S, Stanwell P, Bivard A, Spratt N, Walker R, Kitsos GH, et al The initial of stroke severity on mortality overall functional outcome and in-hospital placement at 90 days acute ischemic stroke. A tertiary hospital stroke register study. Neurol India. 2017; 65(6): 1252-1259.

7. Bhatt A, Leslo A, Lucas L, Kansava A, Baraban E, et al. Patients with low National Institutes of Health Stroke Scale Scores have longer doorto-needle times: analysis of a Telestroke Network. J Stroke Cerebrovasc Dis. 2016; 25(9): 2253-8.

8. Young FB, Weir CJ, Lees KR. Comparison of the National Institutes of Health Stroke Scale with disability outcome measures in acute stroke. Stroke. 2005; 36(10): 2187-92.

9. Quinn TJ, Langhorne P, Stott DJ. Barthel Index for Stroke Trials: development, properties and application. Stroke. 2011; 42 (4): 1146-1151.

10. Balu S. Differences in psychometric properties, cut-off scores, and outcomes between the Barthel Index and Modified Rankin Scale in pharmacotherapy-based stroke trials: systemic literature review. Curr Med Res Opin. 2009; 25(6): 1329-41.

11. Kwakkel G, Veerbeek JM, Harmeling-van der Wel BC, van Wegen E, Kollen BJ. Early Prediction of Functional Outcome after Stroke (EPOS) Investigators. Diagnostic accuracy of theBarthel Index for Measuring Activities of Daily Living Outcome After Ischemic Hemispheric Stroke: does early poststroke timing of assessment matter? Stroke. 2011; 42 (92): 342-346.

12. Huybrechts KF, Caro JJ. The Barthel Index and modified Rankin Scale as prognostic tools for long-term outcomes after stroke: a qualitative review of the literature. Curr Med Res Opin. 2007; 23(7): 1627-36.

13. Quinn TJ, Dawson J, Walters MR, Lees KR. Reliability of the Modified Rankin Scale. A systemic review. Stroke 2009; 40(10): 3393-5.

14. Vogt G, Laage R, Shuaib A, Schneider A. VISTA Collaboration. Initial lesion volume is an independent predictor of clinical stroke outcome at day 90: an analysis of the Virtual 10. International Stroke Trials Archive (VISTA) database. Stroke. 2012; 43(5): 1266-72.

15. Pan SL, Wu SC, Wu TH, Lee TK, Chen TH. Location and size of infarct on functional outcome of noncardioembolic ischemic stroke. Disabil Rehabil. 2006; 30; 28(16): 977-83.

16. Zang RS, Zhang H, Xu Y, Zhang SM, Liu X, Wang J et al. Serum $\mathrm{C}$-reactive protein, fibrinogen and $\mathrm{D}$-dimer in patients with progressive cerebral infarction. Transl Neurosci. 2016; 7(1): 84-88.

17. Muir KW, Weir CJ, Alwan W. C-reactive protein and outcome after ischemic stroke. Stroke. 1999; 30(5): 981-5.

18. Welsh P, Barber M, Langhorne P. Associations of inflammatory and haemostatic biomarkers with poor outcome in acute ischaemic stroke. Cerebrovasc Dis. 2009; 27(3): 247-53.

19. Shantikumar S, Grant PJ, Catto AJ, Bamford JM, Carter AM. Elevated $\mathrm{C}$-reactive protein and long-term after ischemic stroke: relationship with markers of endothelial cell and platelet activation. Stroke. 2009; 40(3): 977-9.

20. Idicula TT, Waje-Andreassen U, Brogger J, Naes H, Thomassen L.Serum albumin in ischemic stroke patients: the higher the better. The Bergen Stroke Study. Cerebrovasc Dis. 2009; 28(1): 13-7.

21. Dziedzic T, Słowik A, Szczudlik A. Serum albumin level as a predictor of ischemic stroke outcome. Stroke. 2004; 35(6): e156-8.

22. Haapaniemi E, Tatlisumak T. Is D-dimer helpful in evaluating stroke patients? A systematic review. Acta Neurol Scand. 2009; 119: 141-150.

23. Feinberg WM, Ericson LP, Bruck D, Kittelson J. Hemostatic markers in acute ischemic stroke. Association with stroke type, severity and outcome. Stroke 1996; 27(8):1296-300.

24. Castellanos M, Serena J. Applicability of biomarkers in ischemic stroke. Cerebrovasc. Dis. 2007; 24 Suppl 1: 7-15.

25. Kim SJ, Moon GJ, Bang OY. Biomarkers for stroke. J Stroke. 2013; 15(1): 27-37.

26. Foerch C, Singer OC, Neumann-Haefelin T, du Mesnil de Rochemont R, Steinmetz H, Siter M. Evaluation of serum S100B as a surrogate marker for long-term outcome and infarct volume in acute middle cerebral artery infarction. Arch Neuro. 2005; 62(7): 1130-4.

27. Nash DL, Bellolio MF, Stead LG. S100 as a marker of acute brain ischemia: a systematic review. Neurocrit Care. 2008; 8(2): 301-7.

28. Bitsch A, Horn C, Kemmling Y, Seipelt M, Hellenbrand U, Stefel M. Serum Tau protein level as a marker of axonal damage in acute ischemic stroke. Europ Neurol. 2002; 47: 45-51.

29. Bielewicz J, Kurzepa J, Czekajska-Chehab, Stelmasiak Z, BartosikPsujek H. Bielewicz J. Does serum Tau protein predict the outcome of patients with ischemic stroke? J Mol Neurosci. 2011; 43(3): 241-5.

30. Zheng GQ, Wang XM, Wang Y, Wang XT. Tau as a potential novel therapeutic target in ischemic stroke. J Cell Biochem. 2010; 109(1): 26-9. 
31. Ovbiagele B, Saver JL. Day-90 acute ischemic stroke outcomes can be derived from early functional activity level. Cerebrovasc Dis. 2010; 29(1): 50-6.

32. Kerr DM, Fulton RL, Lees KR; VISTA Collaborators. Seven-day NIHSS is a sensitive outcome measure for exploratory clinical trials in acute stroke: evidence from the Virtual International Stroke Trials Archive. Stroke 2012; 43(5): 1401-3.

33. Cioncoloni D, Piu P, Tassi R, Acampa M, Guideri F, Taddei S, et al. Relationship between the modified Rankin Scale and the Barthel Index in the process of functional recovery after stroke. Neuro Rehabilitation. 2012; 30(4): 315-22.

34. Matsuo R, Ago T, Hata J, Wakisaka J, Kuroda J, Kuvashiro T, et al. Fukuoka Stroke Registry Investigators. Plasma C-reactive protein and clinical outcomes after acute ischemic stroke. A prospective observational study. PloSone. 2016; 11(6): e0156790.
35. Kuhlmann CR, Librizzi L, Closhen D, Pflanzner T, Lessmann V, Pietrzik $\mathrm{CU}$, et al. Mechanisms of C-reactive protein-induced blood-brain barrier disruption. Stroke. 2009; 40(4): 1458-66.

36. Pepys MB, Hischfield GM, Tennent GA, Gallimore JR, Kahan MC, Bellotti V. Targeting C-reactive protein for treatment of cardiovascular disease. Nature. 2006; 440(7088): 1217-21.

37. Dziedzic T. Systemic inflammation as a therapeutic target in acute ischemic stroke. Expert Rev Neurother. 2015; 15(5): 523-31.

38. Squizzato A, Ageno W, Finazzi S, Mera V, Ranualdi E, Bossi A, et al. $\mathrm{D}$-dimer is not a long-term prognostic marker following acute cerebral ischemia. Blood Coagul Fibrinolysis. 2006; 17(4): 303-6.

39. Sato S, Uehara T, Ohara T, Suzuki R, Toyoda K, Minematsu. Factors associated with unfavorable outcome in minor stroke. Neurology. 2014; 83(2): 174-81.

40. Bentsen L, Christensen A, Christensen H. Outcome and risk factors presented in old patients above 80 years of age versus younger patients after ischemic stroke. J Stroke Cerebrovasc Dis. 2014; (7): 1944-8. 